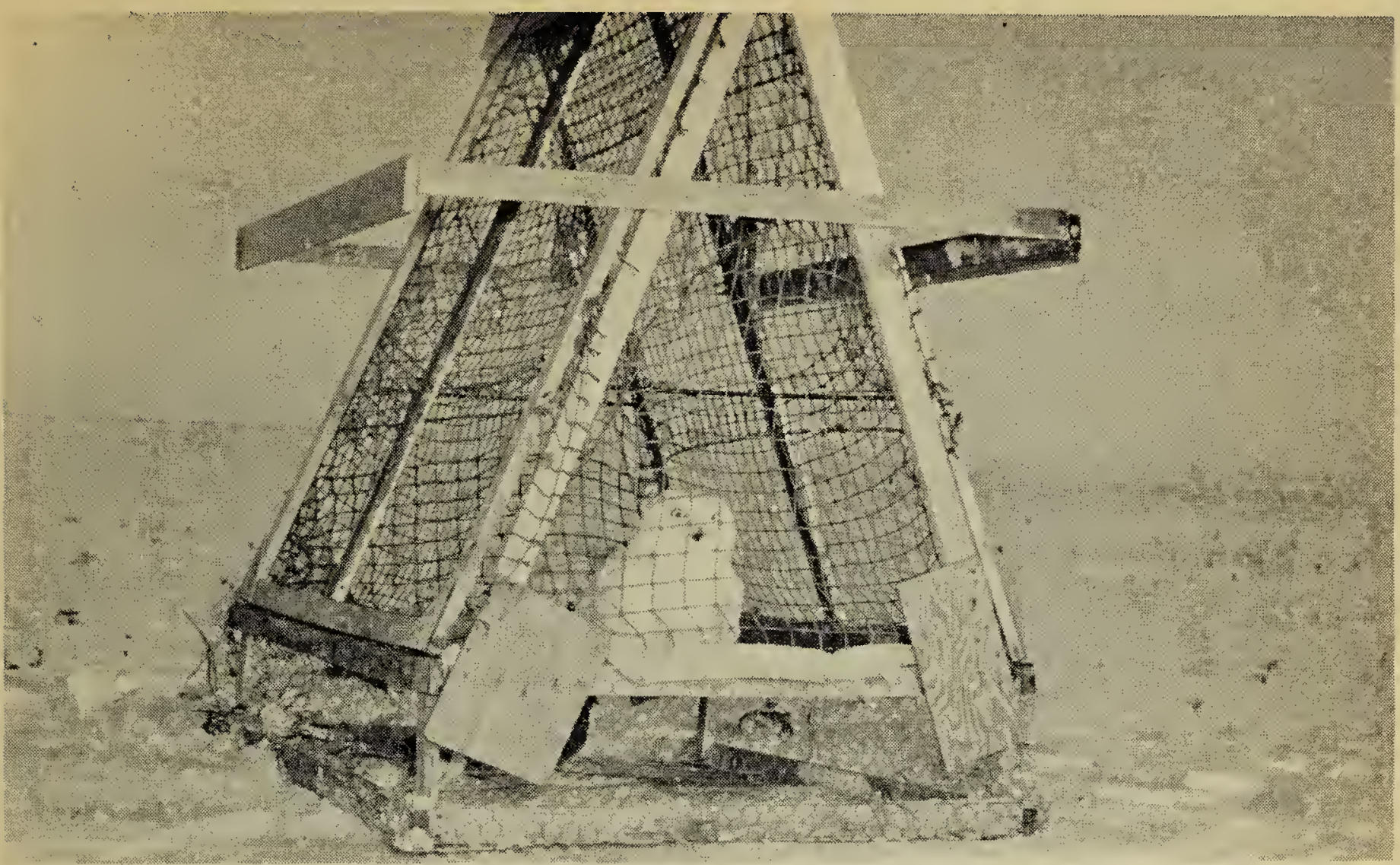

Photo by Fred G. Bard

Snowy Owl trapped in Norwegion Goshowk trap.

\section{DEFORMED HAIRY WOODPECKER}

by George Chopping, Dubuc

On December 8, 1961, a female Hairy Woodpecker approached our feed tray quite shyly. When it settled on the feed tray it almost toppled over. It tried a couple of times to get its balance to feed. On looking more closely I found to my surprise that it had only one foot. The other foot looked as if the circulation had been cut off, for it was all shrivelled up and we could hardly see it. Later on, we saw the bird again. Sometimes it would land on the tray and keep its balance, but other times it had to try two or three times before it would get its balance. It has not been seen since the cold weather came.

\section{REQUEST FOR INFORMATION} MIGRATION OF BUFFLEHEADS -A study of the Bufflehead is under way, and information on the migration of that species is needed. Data required includes first arrival dates, peak date of migration and peak numbers, and departure dates. Only birds actually believed to be migrants should be listed, but, where pertinent, other data on wintering or summering numbers should be included. If only infrequent visits are made to areas frequented by Bufflehead, the statement "present by (date)" is preferable to "arrival (date)", and "last seen (date)" to "departure (date)". Information is solicited particularly for the spring migration of 1962 , but it. is hoped that interested observers will report any data they may have obtained in the past; requests for fall migration data will be made later. It is planned to colour-mark some Buffleheads in Maryland, New York, and Oregon, during the winter of 1961-62, and observers should take particular note of any Buffleheads bearing bright patches of red, yellow, or orange. Please send information on the Bufflehead to: A. J. Erskine, Canadian Wildlife Service, P.O. Box 180, Sackville, New Brunswick.

COLONIAL BIRDS-Since 1961 was especially dry, it is feared that many colonial birds (gulls, pelicans, etc.) will have poor nesting conditions in 1961. Please report abandoned colonies or new colonies to the Saskatchewan Museum of Natural History, Regina.

TURKEY VULTURE-The Museum would like to do film footage on a vulture's nest if any reader finds a nest in 1962. Send particulars to the Saskatchewan Museum of Natural History, Regina. 